\title{
Stay in Your Own Part of the Bookshop! Legitimation in the Literary Field and the Limited Exchange Value of Celebrity Capital
}

\author{
David C. Giles ${ }^{1 *}$ \\ ${ }^{1}$ University of Winchester, West Hill, SO22 4NR Winchester, UNITED KINGDOM \\ *Corresponding Author: David.Giles@winchester.ac.uk
}

Citation: Giles, D. C. (2018). Stay in Your Own Part of the Bookshop! Legitimation in the Literary Field and the Limited Exchange Value of Celebrity Capital, Journal of Cultural Analysis and Social Change, 3(1), 04. https://doi.org/10.20897/jcasc/3114

Published: July 30, 2018

\begin{abstract}
This paper explores the phenomenon of boundary crossing between cultural fields and the role that different kinds of capital play in determining whether or not the crossing is a successful one. The fields in question here are those of entertainment (specifically, stand-up comedy) and literature, and the particular boundary crossing is represented by the figure of Ben Elton, a British comedian who has published 15 novels since 1989, with mixed critical and commercial success. One novel (Popcorn, 1996) received sufficient attention within the literary field to be long-listed for the Booker prize, an accolade usually reserved for writers belonging to the sub-field 'literary fiction'. Others have fared less well, and after many years Elton's credentials as a writer are still queried in some reviews of his work. I suggest that, from a close analysis of reviews in the UK press, Elton's boundary crossing was initially enhanced by the amount of celebrity capital that he was able to export to the literary field. Despite his evident intention to remain a serious practitioner in that field, however, this capital has increasingly diminishing returns, and legitimation of his work is forever hampered by the image of his celebrity persona.
\end{abstract}

Keywords: bourdieu, celebrity, cultural fields, literary field, fiction

\section{INTRODUCTION}

The study of symbolic boundaries in social and cultural life has largely focused on their role in producing inequalities of social class, race and religion (Bourdieu, 1984; Lamont, 2000). In this paper I am examining a somewhat different type of boundary crossing, one in which the agent would appear to carry a good deal of useful capital, but where that capital proves to be of limited use in achieving full legitimation in a different cultural field. I am speaking specifically of celebrity capital (Driessens, 2013) and its exchange value in the literary field, particularly at its high-status end, the sub-field known as 'literary fiction'.

Celebrity capital has been conceived as "accumulated media visibility that results from recurrent media representations" (Driessens, 2013, p. 543), and enables celebrities to cross from unrelated fields such as entertainment into politics (Arthurs and Shaw, 2016), or across boundaries that separate high-status fields from lower ones, such as Paul McCartney's migration from popular to classical music (Giles, 2015). However, as the case of McCartney suggests, while celebrity capital can secure a foothold in a higher status field it does not guarantee legitimation in that field if other important credentials are required, such as the cultural capital accumulated through formal education within that field.

The literary field, like the musical field broadly conceived, consists of a similar hierarchy, particularly where fiction is concerned. At the top is found the rarified subfield of literary fiction, a category that has been largely invented by publishers and booksellers in recent years to indicate "quality" or "highbrow" fiction, although its 
distinguishing criteria are mainly industrial rather than aesthetic: "a set of publishing processes and practices which include not only the composition and editing of the book but also its design, marketing and distribution, as well as, most distinctively, its relationship with particular institutions such as literary prizes and broadsheet reviews" (Norman, 2011, p. 38).

It is these last two institutions which have particular relevance for the case study I will go on to present. The Booker prize was established fifty years ago in order to reward "the best novel of the year written in English" with the broad aim "to increase the reading of quality fiction" (The Man Booker Prize, 2018). Winners have included some of the most prestigious and celebrated British and Commonwealth (and since 2016) American writers and, although not explicitly stated anywhere, the assumption is that novels selected for the 'long' shortlist are exclusively drawn from the literary fiction category. The second institution Norman mentions is "broadsheet reviews", referring to book review sections of the UK national press, though only those from the 'quality' end of another hierarchy - those traditionally larger-sized publications such as The Guardian, The Times and The Independent. I will refer extensively to both "institutions" throughout the course of this article.

The case study that I will use to explore this particular boundary crossing is that of Ben Elton, a British standup comic and TV scriptwriter who has enjoyed considerable commercial success as an author as well as receiving some legitimation within the literary field, most notably the nomination of his 1996 novel Popcom for the 'long list' of the Booker Prize. At the same time, during his three decades as a novelist, critical reviews of Elton's work have often worked to discredit this legitimation, and, through close analysis of his novels' reception in the UK "broadsheet" press I will discuss the ways in which this has been achieved. First, however, I will discuss some of the specific aspects of comedy that are relevant to this case study, and review the literature on the practice of book reviewing.

\section{Comedians and the Literary Field}

According to Bourdieu (1993, p. 165), the writer enjoys a 'double status', as orator ('saying the true and the good') and fool ('to whom is accorded transgression without consequences'). It is perhaps no surprise, then, that so many British comedians - to whom the same double status surely applies - have recently made the boundary crossing from stand-up comedy into the literary field. Since Ben Elton made his literary debut with the comic novel Stark (1989), no fewer than 40 novels ${ }^{1}$ have been published by authors who are best known to the public for their appearances on UK television or on stage as, primarily, comedians. While Elton's own oeuvre accounts for a substantial chunk of this output (15 titles to date), other names include Stephen Fry, Dawn French, David Baddiel, Robert Newman, Stewart Lee, Hugh Laurie, Alexei Sayle, and Jenny Eclair.

There is not a long tradition of British comedians entering the literary field. Spike Milligan's Puckoon (1964) was a rare critical and commercial success, selling over 6 million copies and featuring in various lists of the best comic novels of all time, but there are no precedents for comedians enjoying success in non-comic genres, and certainly not the coveted genre of 'literary fiction'. Inevitably, then, most comedians-turned-novelists have begun their writing careers opting for the familiar format of comedy, only attempting to branch out into other genres after having secured a safe footing in the broad literary field.

On the face of it, comedians are uniquely equipped for a second career as authors of fiction. They are gifted storytellers, crafting anecdotes to please an audience (stage comedians receive instant feedback), and share the same outsider status as 'the writer' - that is, the literary author as conceived by Bourdieu (whose model was essentially Flaubert, described by Sartre as "the village idiot"). Caught between the two opposing poles of bourgeoisie and the proletariat, and above all fully independent, artists need (Bourdieu, 1993: 169) 'to free themselves from bourgeois demands and define themselves as the sole masters of their art'.

This spirit of independence extends to politics, another field in which comedians have enjoyed some recent influence, albeit as popular activists (most notably the Italian Beppe Grillo but also the British comedian Russell Brand). Again it is the perceived neutrality of comics arising from their outsider status that lends weight to their claims to represent the public voice (Arthurs and Shaw, 2016). Stand-up comedy is a particularly effective vehicle for communicating political ideas: as Quirk (2015) argues, the perceived (unmediated) neutrality of the theatre stage allows performers to try out routines that would be unacceptable on television (the same applies to online media like YouTube). Indeed it is a long-standing tradition for stand-up comics to release 'live and uncensored' recordings that remind audiences of their position outside the constraints of regulated media. It is perhaps no coincidence that most of the comedians-turned-novelists began their comedy careers in this format.

\section{The Institution of Criticism}

How do writers become legitimated within the literary field? Van Rees (1987) identified three levels of criticism that perform this function: the journalistic level, through reviews in national newspapers; the essayist level, through more extensive discussions of work in literary magazines and journals; and the academic level, where work is

${ }^{1}$ Specifically novels aimed at a broad adult readership (excluding at this point books aimed at children, which I will discuss briefly later on) 
formally scrutinised and selected for course curricula. Together these constitute what Janssen (1997) terms 'the institution of criticism', where, through a gradual process of 'orchestration', certain writers are granted legitimation (often just determined by critical attention, e.g. which books are actually reviewed) and others condemned to obscurity.

In this paper I am going to focus entirely on the journalistic level of criticism of Ben Elton's work because it would seem to be the most relevant given Elton's very high existing media profile at the outset of his literary career (indeed this would be the case with any existing celebrity who decides to publish literary work - as opposed to authors who attain celebrity solely on the basis of their writing). In relation to Bourdieusian theory, reviewers in national newspapers would seem to correspond with his description of a 'corps of professionals appointed to conserve the work of art, both materially and symbolically' (Bourdieu, 1993, p. 36) who produce 'meaning and value' (ibid, p. 37), apeing 'the learned, sententious tone and the cult of erudition characterising academic criticism' (ibid, p. 131). Ultimately, reviewers have to decide whether a work of art is sufficiently detached from commercial interests to be taken seriously. The importation of celebrity capital then immediately sets up a degree of suspicion - is this individual simply 'cashing in' on their fame?

There are other functions of critical legitimation that are unique to the literary field. These include the formal quality of the writing itself - the intrinsic properties of prose style such as word choice, grammatical consistency, and the use of recognised literary devices - as well as the treatment of setting, narrative and character development deemed to be necessary evaluative criteria for a novel (Corse and Griffin, 1997). Despite the apparently objective nature of such criteria, it has been argued that critical legitimation is largely arrived at through orchestrated consensus, whereby critics 'attune their judgements to each other' (Janssen, 1997, p. 277). Partly this is a protective strategy to maintain the status of the critics themselves. It may also have a basic social function; as de Nooy (1999) has argued, reviews have interpersonal consequences - in terms of their relationships with authors - for those who write them. Apart from anything else, journalistic critics are often published or aspiring authors themselves.

\section{Ben Elton: From Stand-up to the Booker (and Back?)}

When Ben Elton published Stark in 1989, he was one of the most recognisable figures in British popular culture. Compère of the BBC's variety show Friday Night Live and co-author of the classic sitcom Blackadder (which was just about to air its fourth and final series), he personified 'alternative comedy' for the mass audience with his abrasive and electrifying delivery, with frequent attacks on then Prime Minister Margaret Thatcher, perhaps best captured on the live 1987 LP Motormouth. Stark, a comic novel with an environmental theme (aiming satire at politicians and eco-activists alike) was an immediate success for Sphere books, selling well over a million copies, and was followed by four further novels for Simon and Schuster. The last of this series, Popcom (1996), tackled the subject of violence inspired by Hollywood film (in the wake of the media outcry around Oliver Stone's Natural Born Killers) and became Elton's first genuine critical success, winning the Crime Writers Association's Golden Dagger award and being longlisted for the Booker Prize ${ }^{2}$. Subsequent novels fared less well critically, despite continuing commercial success: Nielsen Bookscan listed Elton as the 58th best-selling author for all books sold in the UK over the 2000-2009 decade.

Thematically his fifteen novels can be grouped into three phases: the early (often environmentally-orientated) comic farces borrowingly liberally from his stage act material; the middle period (from Popcorn onwards) in which contemporary issues - such as reality TV and drugs - form the setting for a murder mystery; and the later period (from 2005's The First Casualty), which sees him draw on historical, typically wartime, settings. These last two phases can be distinguished by the visual appearance of the paperback editions: the mid-period covers are vividly colourful, trumpeting 'No. 1 bestseller' even at the point of release, while the history-themed novels have elegant, sober covers with embossed lettering, in the style of the literary fiction genre. (This apparent development is not necessarily reflected in critical appraisals of the work, as I will go on to argue later.) Elton's literary career has unfolded in conjunction with other successful writing ventures including musical shows and plays, as well as scripts for TV series, though since Blackadder these have attracted increasing criticism from peers and reviewers.

In the next section I will present an analysis of some of the critical reviews of Elton's novels, taken from the archived content of British newspapers held by the News Bank dataset. I have concentrated almost exclusively on reviews in the 'broadsheet' newspapers (Guardian, Times, Independent, Telegraph and their Sunday equivalents), given their legitimizing role within the field of literary fiction. By taking an iterative approach derived from methods such as thematic analysis (Braun and Clarke, 2006) and grounded theory (Strauss and Corbin, 1998), I identify a number of broad patterns and common elements throughout the reviews which describe the way in which critics have evaluated Elton's work.

\footnotetext{
${ }^{2}$ It should be noted that Popcorn had the good fortune to be published before the Booker organisers shrunk the long list to less than half its previous size at the beginning of the current century (from around 30 to the current 13).
}

(C) 2018 by Author/s 


\section{THE CRITICAL RECEPTION OF BEN ELTON'S NOVELS}

\section{"The Motormouth Comedian in a Spangly Suit": Depicting the Author}

"I still have this comic-writes-fourteenth-novel thing" says Ben Elton in one of his frequent press interviews (1). A great many reviews of Elton's novels contain, often in the first sentence, a stereotypical image of the author in a decidedly non-literary context. The intent here is often to present Elton as confounding expectation, either by writing a novel in the first place, or by continuing to publish. At other times, it is simply a device for accounting for the particular book's perceived limitations ("unsurprisingly for a man who first flourished as a stand-up comedian..." (2)). In either case, it serves to frame the author in the context that will be most recognisable to readers, typically in his 1980s stand-up persona, and occasionally, usually to set up an unflattering comparison, as co-writer of Blackadder.

The stand-up persona is surprisingly ubiquitous in the reviews because it is typically captured by a set of striking images: the performer in the "spangly suit" 3 and outsized spectacles with a "manic" or "motormouth" delivery, cracking jokes about "Mrs Thatch". The most frequently impersonated celebrities, such as Elvis and Charlie Chaplin, are those whose image can be conveniently reduced to a set of signifiers (Giles, 2017), but in the process the individual artist becomes frozen at a specific moment in their career. In the same way that Elvis is forever strutting around a Vegas ballroom, Elton has been immortalised in a manner that does not sit comfortably with the image of a serious (even seriously comic) novelist.

Later reviews, while still occasionally referencing the stand-up persona, begin more frequently to use his previous novels as points of comparison. Meltdown (2009) is unfavourably compared to Popcorn (1996), the latter being "very funny and sharp" (4), although the same review still drags stand-up in by alluding to one of his 1980s catchphrases ("he's got to get in his little bit of politics"). As early as 1996 a reviewer describes Elton as "an 'issues' novelist" whose latest novel represents something of a departure (5); by 2005 his shift from murder mysteries to historical fiction earns him the criticism that he "should stick to comic crime writing" (6). One particularly effusive review of the same novel (The First Casualty) actively seeks to reconstruct Elton's image for the reader: "Put aside any remaining thoughts of Ben Elton in his shiny jacket and start to think of him as a real writer" (7).

A very common theme in reviews of Elton's novels, particularly in right-wing newspapers, is the claim that he has moved away politically from his stand-up period. Reviewers in the Times and Telegraph - notably some of the most positive - frequently express surprise at the moralistic tone of the novels, particularly those from around the end of the millennium. One of the most friendly reviews of Popcorn (1996), in many respects Elton's watershed novel, celebrates his perceived turn to conservatism ("reactionary humour at its most engaging") and claims that he "will end up writing for The Spectator [right-wing cultural magazine] if he carries on like this" (8).

Telegraph critics in particular seek to cast Elton in the mould of 1950s 'angry young men' such as Kingsley Amis (cited in both (9) and (10)) and John Osborne: like these figures, Elton is perceived - favourably - as a young leftwing firebrand who sensibly mellowed into establishment conservatism in middle age. Such endorsements often come with a hint of nostalgia for the days in which he could be relied upon for a good "rant" about "Thatch", even to the point of seeing the mid-2000s Elton as "disturbingly conservative" (11), and can be read as part of a 'maturation' narrative that characterises several of the most positive reviews. One writes of his "journey...to fullblown curmudgeon" (10); another of "a once-angry young man whose rage is becoming fascinatingly reactionary" (9). Even the Guardian, referencing a somewhat different literary figure, claims that "he is becoming decidedly Pooterish in his prime" (12). In each case, the reviewer seems to suggest that Elton's satirical gifts are slightly wasted on the media topics that form the settings for the mid-period novels: screen violence (Popcorn), reality TV (Dead Famous), TV talent shows (Chart Throb).

By the time Elton's literary career enters its latest, history-themed phase, the more positive reviews seek to distance the work even further from the "shiny suit" caricature. In the most glowing critique of all, the Telegraph review of The First Casualty declares: "it is impossible to believe it was written by the same man who used to tell stories about going to the loo in nightclubs." (7).

\section{Damned with Faint Praise: Ben Elton as 'Non-writer'}

The next theme I have identified follows on from the first, in that it extends the rhetorical function of references to Ben Elton's stand-up persona: namely, the framing of Elton as literary outsider or even interloper. This is a rite of passage that all celebrity authors must endure in order to be fully legitimated, because the effectiveness of celebrity capital is such that the literary critic feels obliged to perform the function of cultural intermediary. Even

\footnotetext{
${ }^{3}$ The numerous references to 'spangly' or 'shiny' suits are not really borne out by the archived performances available on YouTube from the Friday/Saturday Night Live period. In most of these he is wearing a fashionable Yuppie-era suit, but there is only one video in which the jacket conspicuously sparkles. Most curious of all is the review (3) in which it is claimed that Elton has 'long ago hung up his donkey jacket' - sartorially just about the antithesis of the sparkly suit.
} 
though the work of Elton and other celebrities will have inevitably undergone the scrutiny of agents, editors and other publishing industry professionals, there nevertheless remains a suspicion that the author has not taken "the proper path to publication", as Levey (2016) says, ironically, in relation to self-publishing.

In this respect, references to celebrity status in reviews of Elton's books serve the same function as postimpressionist painter Henri Rousseau's nickname 'Le Douanier', which is so frequently used in lieu of his proper name that it is easy to overlook the fact that it was initially a jibe at his former profession of customs officer. The sobriquet has remained in place to remind people that Rousseau was not a 'true' or professional artist (Bourdieu, 1993, contrasts him with the much better-connected Marcel Duchamp, whose 'readymades' were framed as iconoclastic artistic comment rather than naif art). Likewise, descriptions of Elton in his "shiny suit" berating "Mrs Thatch" remind readers that he is not a 'born to the manner' novelist but one who has travelled into the literary field on a celebrity passport.

The image of the outsider permeates even some of the quite favourable reviews, two of which are worthy of close scrutiny, both of High Society (2002). This novel saw Elton take on the complete legalisation of drugs, a position that, according to Will Hutton in the Observer (13), the author is passionately in favour of; the paper's byline to the review even refers to it as a "crusading novel". Hutton's review begins by admonishing Elton for what he sees as an unwriterly and thereby clumsy attempt to impose his own views on his characters, describing him as "a very good comedian abandoning his craft and lumbering into the pulpit to preach". The message here is emphatic: stay in your own field (comedy). He builds to a positive note, however, arguing that the book is "saved by its pace and the author's passion for his subject". He concludes, rather in the manner of a schoolteacher commending a weaker student's essay: "This is a tough subject tackled with courage and commitment. The great Victorian novelists managed to crusade and to entertain. Elton's book, despite its weaknesses, is cast in that tradition." In other words: not bad for a comedian.

Meanwhile, in the Sunday Telegraph, it seems as though David Robson (14) has been allocated a different book altogether. "Where does Ben Elton stand on the regulation of drugs? I have no idea. Nor will the reader of High Society have any idea." This apparent ambiguity is a "tribute to the book's even-handedness." But this is not a lucky accident incurred while blundering out of the author's proper field: it is the mark of a gifted writer. "Superior novelists do not take sides," Robson argues, "and Elton is now, against expectation, a superior novelist." Like Hutton, although for contrasting reasons, this reviewer ends up being somewhat ambivalent about High Society: "not one of his strongest books... a lightweight piece...but as a comic entertainment, it is both well observed and easy to read".

As I will consider in more detail in the next section, one of the most striking features of reviews of Elton's work is how little consensus there is on the question of his writing ability and on the qualities of individual novels. Much of this variation is, I believe, the result of his 'back door' entry into the literary field. Lacking a common literary reference point, reviewers take each novel at face value. A third review of High Society provides further evidence of this fractured consensus, from the Independent. Like the Sunday Telegraph reviewer, Susan Jeffreys (15) is unable to discern Elton's position on drugs ("difficult to tell, from this novel, where Ben Elton stands"), but this is due to what she interprets as his indifference to the subject ("his heart doesn't always seem in the [prolegalisation] argument"), arguing that, as the book progresses, he "seems to lose interest in some of [the storylines]". While Hutton in the Observer contrasts the novel condescendingly with "the great Victorian novelists", Jeffreys chooses a previous Elton work (which she herself had reviewed enthusiastically the previous year (16)) as an unflattering point of comparison: the "impressive" Dead Famous, against which High Society "isn't quite in [the same] class".

The outsider/interloper theme appears frequently in qualified comments about the merits of Elton's writing, typified by David Robson's aside about Elton being a superior novelist "against expectation" (14). A common practice is to praise positive elements of his craft in order to dismiss others, so a plot is "robustly structured and paced so nicely as to distract the eye from most of the book's inconsistencies", with prose that is "soothingly anodyne" (7); a narrative that is "effective without any style at all" (17); a "competent detective story" (19). There is occasionally the hint that a successful work may have been a fluke (this is perhaps the sense of Jeffreys's reference to Dead Famous (15)): a similar reference is made by Jenny Colgan, reviewing Meltdown unfavourably in the Guardian (4), to the much-earlier Popcorn ("very funny and sharp"). At the time, Popcorn was one of the most positivelyreceived novels, but even then the quality of the work was acclaimed as a "big surprise" in one review (8), and patronised as a "grown-up book" in another (18).

This last comment relates back to the maturation narrative discussed earlier, whereby the celebrity-turnednovelist is perceived as learning on the job, as distinct from the bona fide writer who, it is assumed, could not have been awarded a book contract without a certain degree of literary polish. Changes in thematic content or setting provide opportunities for reviewers to note signs of progress in Elton's output (for example, Popcorn's "writing is more settled and less attention-seeking than it has been" (5)), and the fertility comedy Inconceivable (1999) is praised 
for being based on personal experience rather than topical issues, and in which "[Elton] learns to write from the heart". (19)

\section{Can Ben Elton Write?}

Whom do editors commission to review books? Certain critics seem to be habitually assigned the new Ben Elton each time, regardless of their appraisal. David Robson (Telegraph) crops up three times in the archive, initially as an enthusiast; however, his review of Blind Faith (2007), a novel seemingly overlooked by most newspapers, is one of the most damning of the entire sample. Jenny Colgan (Guardian) is asked to review Two Brothers in 2012 after panning Meltdown in 2009; Henry Sutton (Independent) surfaces from time to time to administer a bashing. Much of the time, however, Elton's books seem to be allocated to somebody who is not familiar with his earlier novels, which may partly account for the repetitive use of 1980s stand-up imagery in the opening paragraph of so many reviews. It might also account for the lack of consensus in appraisals of the literary qualities of the work.

Just as reviewers were unable to agree on Elton's position on the legalisation of drugs in High Society, they are rarely in accordance on either the quality of the prose in his novels or on the success of the characterisation. The same writing is described, across various books, as "inelegant", "tired and slack", "excruciating" and "laboured", but elsewhere, "brilliant", "good" and "terrific". The characterisation is described in some reviews as "poor", "onedimensional" (twice), "mechanisms, not people", yet other critics (not necessarily in positive reviews) find the characters "warm-hearted", "beautifully delineated" and "well-drawn".

Reviewers seem to have particular trouble agreeing on the merits of the first war novel in Elton's most recent phase, The First Casualty (2005), in which he revisits the First World War setting associated with so much acclaim for the Blackadder series. I have already cited from Toby Clements's review in the Telegraph (7), but to this eulogy can be added the review by Melissa Katsoulis in the Sunday Telegraph (21): "some dodgy plotting can be overlooked when the prose is good - and in parts Elton's is brilliant...unputdownable and disgustingly realistic." Other reviewers, however, dismiss the novel as "preposterous" (22), "ponderous and pompous" (6), "tragically flawed" (23), unsubtle and "melodramatic" (2).

Unanimity among critics finally arrives with the most recent two novels in this tradition, Two Brothers (2012), a novel set in pre-Second World War Berlin, and Time and Time Again (2014), a time-travel thriller set partly in the run-up to the First World War. It is surprising to see historical fiction criticised for being too well-researched, but Helen Rumbelow's claim in the Times that Time and Time Again is "hyper-researched" (24) chimes with most other reviews of these two works. Research is good, the consensus seems to be, but not when the writing is weighed down with historical "exposition". Almost every review lambasts the latter, as "finger-wagging" (20), "clunking" (25), "heavy-handed" (26); the prose full of "obvious research-won 'facts' about Berlin in the 20s" (24) resulting in "stilted dialogue" (27). Rumbelow rubs salt in the wound by comparing Time and Time Again with a recent "alternative history" novel by double Costa book award winner Kate Atkinson: "her writing is beautiful, while Elton's is effective" (24).

The unflattering comparison is not an unusual device for showcasing Elton's perceived limitations as a writer. At the time of Dead Famous (2001), a writer with slightly higher literary pedigree, Mark Lawson, had published a similar novel satirising reality TV in the wake of the first UK series of Big Brother, and two newspapers chose to run reviews of the novels in tandem (one of the two reviewers concluded by recommending readers to "buy both"). The following year, the Sunday Times carried a similar parallel review featuring High Society and John O'Farrell's This is Your Life, a comic novel about celebrity, which was praised for having "more distance - and hence sharper satire" (28).

So, can Ben Elton write? Much depends on what he is writing about, when he is writing it (abrupt changes in style seem to fare better than the prolongation of a particular format), and whomever has been assigned to write the review. It is evident that critics find it difficult to agree exactly what kind of writer he is: Booker longlisted in 1996; merely "effective" in 2014. Ironically, it is the two most recent novels whose packaging has been designed with the apparent intention of moving Elton away from the popular crowd towards a more sophisticated literary readership. Figure 1 contrasts the cover design for The First Casualty (2005) and Chart Throb (2006), whose bright colours, bold typefaces and claims of 'bestseller' clearly target a mass audience, with that for Two Brothers (2012) and Time and Time Again (2014), featuring tasteful, subdued images, with the latter's title embossed in elegant gold lettering. Perhaps the most striking difference lies in the presentation of the author's name: for the first two books - in common with most of the pre-2012 titles - it occupies nearly half the cover space, screaming 'celebrity author', while for Time and Time Again in particular it is barely noticeable at first glance, the eye being drawn to the first word of the book's title. Despite the best efforts of marketing professionals, though, reviewers have conspicuously failed to adjust their perspective of Elton as an author. 


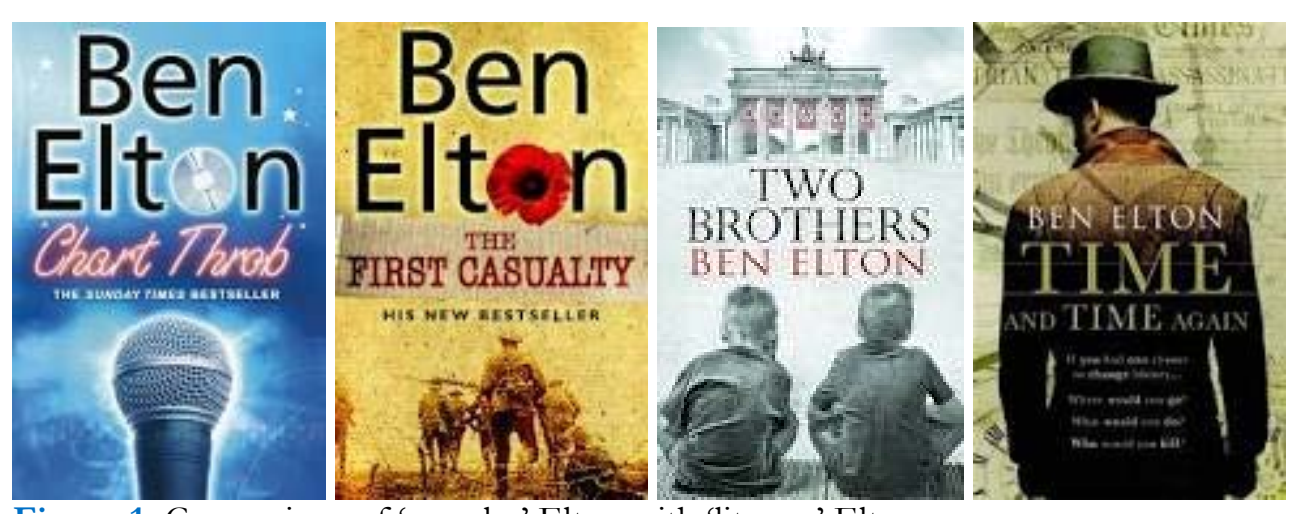

Figure 1. Comparison of 'popular' Elton with 'literary' Elton

\section{'Middlebrowness'}

"I have middlebrow tastes, so perhaps that's why I write middlebrow work" (Ben Elton, in 29)

This next theme more explicitly concerns reviewers' attempts, either implicit or explicit, to place Elton's work within a specific literary tradition or genre. As far as publishing companies' marketing departments are concerned, cover design performs an important function here, if only to persuade booksellers to organise the shelving accordingly. But within the broad domain of 'fiction' there is a clear hierarchy based on (perceived) genre, with 'literary fiction' at the summit, and other genres (crime, young adult, etc.) at various positions below. These genres can be mapped further on to long-standing notions of 'highbrow' and 'middlebrow' fiction, which equate roughly to Bourdieu's (1993) distinction in 19 th $^{\text {th }}$ century France between the serious art novel (epitomised by the work of Flaubert) and the popular serialised 'feuilletons'.

Seventy five years later, the debate over the distinction between high- and middlebrow fiction continues to rage around contemporary publishing practices (Jaffe, 2015). Virginia Woolf, albeit with tongue firmly in cheek, defined "the middlebrow" as a person "in pursuit of no single object, neither art itself nor life itself, but both mixed indistinguishably, and rather nastily, with money, fame, power or prestige" (1942, p. 155). A more recent analysis has concluded that the middlebrow is defined by eight key features: middle-class, reverential towards elite culture, entrepreneurial, mediated, feminised, emotional, recreational and earnest (Driscoll, 2014). This is consistent with Bourdieu's (1993) argument that (serious) literature has symbolic power assigned to it by critics that overturns the usual operation of economic laws, so that the word 'bestseller' becomes (in the literary field at least) a term of contempt rather than an accolade.

Part of the problem is that the genre "literary fiction" is so slippery, so hard to define. While Norman's (2011) definition (cited earlier in this article) might allow us, at least superficially, to distinguish between literary fiction and an unambiguously thematic genre such as crime or sci-fi, it is hard - if not impossible - to specify the cut-off point below which a work is insufficiently 'literary' to qualify as a legitimate member of this elite category. Irrespective of decisions made by marketing departments (such as the packaging of Elton's historical novels), it is ultimately the work of critics that determines the literary status of a specific book and its author.

Sometimes this designation is accomplished by reviewers allocating their own criteria. One might not think that a book could be "too topical", but this is the basis of Jenny Colgan's dismissal of Meltdown (4), as well as its being "extremely readable". In a later review, Colgan criticises Two Brothers for being "readable as an Archeresque yarn" (20) (Jeffrey Archer here being the touchstone for middlebrow fiction). For these reviewers, literary fiction needs to make certain intellectual demands on a reader, and should shy away from a setting that grounds it too firmly in its own epoch. Another review (30) dismisses Dead Famous as a "poor offering...even by the humble standards of its genre". Since, in Elton's case, genre is ambiguous, this leaves the reader to guess which genre the reviewer is referring to solely on the basis of their previous comments about the novel's absorption in television culture.

As Bourdieu (1984) points out, classification judgements assign not only cultural products but critics themselves to categories. One early review (31) described Elton's debut Stark as "not the kind of book I usually read", elevating the reviewer at the same time as dismissing the author. A more subtle way of achieving the same effect is to draw a direct comparison between Elton and an author of (perceived) higher literary status, as in Helen Rumbelow's (24) unflattering contrast with Kate Atkinson's "beautiful writing" 4 . She goes on to say: "That's not to denigrate Ben Elton; in its own part of the bookshop Time and Time Again triumphs and it's the best I've read of Elton's many bestsellers." Again, here, the allusion to genre is paradoxical because bookshops do not generally discriminate

\footnotetext{
${ }^{4}$ Kate Atkinson is a surprising point of contrast, since she is equally renowned for her genre (crime) fiction as for her 'literary' work, which are presumably segregated into two separate sections of the bookshop. There is also the perception among some that her reputation as an author of 'bestsellers' counts against her own legitimation in the literary field, leading her to be overlooked for even the long list of the Booker prize (Crompton, 2014), though she has won numerous other prestigious awards.
} 
between 'literary' and 'middlebrow' fiction. Nevertheless, the point is clearly understood. Elton is not quite one of 'us'.

\section{CONCLUSION}

Perhaps the most striking feature of Ben Elton's critical reception as a novelist is the apparent lack of consensus between reviewers across different newspapers, different books, and different time periods. Many reviewers, even those of his later books, seem to come to his work afresh, and feel obliged to begin their reviews by alluding to his stand-up history. There is often surprise at the number of books he has written. As a writer, Elton seems to be under continuous assessment: each time a new book appears, his right to be reviewed, taken seriously, published even, is under scrutiny. In his case at least, the claim that the 'institution of criticism' orchestrates consensus (Janssen, 1997) is well wide of the mark. If there is consensus here, it is in the institution's reluctance to legitimate Elton as a bona fide novelist.

How much of this can be attributed to Elton's status as a celebrity? Clearly, there are elements in the writing itself that make it hard to defend Elton as a serious novelist. Although his own self-categorisation as 'middlebrow' carries a slightly bitter flavour, it does not help his cause. The charge of being 'too topical' is in part upheld because Elton himself is so open about the influence of the media in his work (for example, he admits (29) to having been inspired to write Past Mortem after reading an article in the music magazine $Q$ ).

One of Elton's biggest problems is that, in writing about contemporary issues, he effectively invites critics to see himself as a character in his own work. There is much discussion in reviews about the author's own critical standpoint on the issues involved, and which characters are articulating his views. A reviewer of Dead Famous asks of the writer: "I couldn't work out whether he abhors [Big Brother]: I doubt he has missed an episode" (32). That the question matters indicates the difficulty reviewers have of separating the text from the "motormouth in the sparkly suit" whose trenchant opinions are believed to lie behind its creation. It may also explain Elton's eventual move into historical fiction (a direction taken, at a similar stage in their writing careers, by other celebrity comedian authors such as Stephen Fry and David Baddiel). Here, however, it is his research, rather than his opinion, that is heard tumbling out of character's mouths.

At this point I shall return briefly to Paul McCartney, another instance of a successful performer in one field (popular music) seeking legitimation in another, higher status field (classical music) (Giles, 2015). Both he and Elton are revered for their work in their original fields - not a bad word is ever said in reviews about McCartney's popular recordings, or Elton's (early) television comedy - to the extent that one is reminded of Arnold Schoenberg's famous put-down to George Gershwin when he approached him for tuition: "I would only make you a bad Schoenberg, and you're such a good Gershwin already". ${ }^{5}$

The pattern of critical reception, and struggle for legitimacy, is broadly similar in each case: occasional recognition (awards, nominations) outweighed by a large volume of negative appraisal, largely from broadsheet reviewers. While much of this struggle can be attributed to cultural snobbery or elitism, there is also a degree of hubris and audacity on the part of both Elton and McCartney in pushing their questionable credentials in a different cultural field. Early successes (such as the Booker listing of Popcorn) have encouraged the artists and their publishers (or commissioners in McCartney's case) to plough on, disregarding the bad reviews, long after the institution of criticism's well of patience has run dry.

My principal focus in both studies has been on the aspect of celebrity as a form of capital that is only partly convertible when transferred to a new field. While Elton and McCartney have tried to convert celebrity status into success in a cultural field further up the hierarchy of distinction, it can be equally difficult for celebrities in higherstatus fields to convert their celebrity downwards, as demonstrated by the relative failure of genre novels written by well-known purveyors of literary fiction such as Martin Amis (Norman, 2011). Ultimately, the most successful boundary crossers (or at least the most comfortable) are those who respect the hierarchy and are able to slip from one field to the other even if it means donning a disguise: a good example here is Booker Prize-winning novelist John Banville, who writes crime fiction under the alias Benjamin Black, and has referred to his dual identity as "two completely different writers" (Ellis-Petersen, 2014).

I want to end this paper with some consideration of changing cultural practices on the whole question of legitimation and critical evaluation. There is little doubt that the critical elite, as represented here by broadsheet reviewers, is under considerable threat from the groundswell of amateur reviewers found in the many online literary blogs and websites. In a study of consumer reviews published on Amazon, Allington (2016) shows how elite cultural values can be undermined by a commercial readership so that a rapturously received Booker Prize winner can now be exposed to criticism on a hitherto unprecedented scale.

\footnotetext{
${ }^{5}$ This anecdote is reported in multiple sources, although an alternative anecdote has also done the rounds featuring Ravel in the place of Schoenberg: at least one Gershwin biographer (Schwartz, 1973) has suggested that they are both apocryphal.
} 
The institution of criticism has managed throughout recent history to orchestrate its consensus largely untroubled by the reception of the readership at large, but this may well be changing. What impact this will have on the literary canon remains to be seen: will popular authors like Ben Elton one day be hoisted on to the pedestal to take their place alongside Shakespeare, Tolstoy, and even Kate Atkinson? More likely is a scenario in which the pedestal itself simply disappears, as Bourdieu's commercial and restricted 'spheres' fuse together, leaving the novel - literary fiction included - as just another commercial product like soap and toothpaste.

\section{NEWSPAPER REVIEWS AND ARTICLES CITED}

(1) Ben Machell, Times, interview (2012)

(2) Chris Power, Times, review of High Society (2002)

(3) Adam Lively, Sunday Times, review of Past Mortem (2004)

(4) Jenny Colgan, Guardian, review of Meltdown (2009)

(5) Nick Barker, Independent, review of Popcorn (1996)

(6) Matthew Lewin, Observer, review of The First Casualty (2005)

(7) Toby Clements, Telegraph, review of The First Casualty (2005)

(8) Phil Baker, Sunday Times, review of Popcorn (1996)

(9) Charles Spencer, Telegraph, review of Dead Famous (2001)

(10) James Walton, Telegraph, review of Chart Throb (2006)

(11) Sunday Times, interview (2006)

(12) Lisa Allardice, Guardian, review of Dead Famous (04/11/01)

(13) Will Hutton, Guardian, review of High Society (2002)

(14) David Robson, Sunday Telegraph, review of High Society (2002)

(15) Susan Jeffreys, Independent, review of High Society (2002)

(16) Susan Jeffreys, Independent, review of Dead Famous (2001)

(17) Russell Celyn Jones, Times, review of Past Mortem (2004)

(18) Michael Bywater, Independent, interview (1996)

(19) Mike Pattenden, Times, review of Inconceivable (1999)

(20) Jenny Colgan, Guardian, review of Two Brothers (2012)

(21) Melissa Katsoulis, Sunday Telegraph, review of The First Casualty (2005)

(22) Jane Jakeman, Independent, review of The First Casualty (2005)

(23) Henry Sutton, Mirror, Worst Books of 2005

(24) Helen Rumbelow, Times, review of Time and Time Again (2014)

(25) Ben East, Observer, review of Two Brothers (2012)

(26) Elena Seymenliyska, Telegraph, review of Two Brothers (2012)

(27) Nick Remison, Sunday Times, review of Two Brothers (2012)

(28) Adam Lively, Sunday Times, review of High Society (2002)

(29) Stephanie Merritt, Observer, interview (2004)

(30) article in The Scotsman (2001)

(31) review of Stark (1989)

(32) Victoria Lane, Telegraph, review of Dead Famous (2001)

\section{REFERENCES}

Allington, D. (2016). 'Power to the reader' or 'degradation of literary taste'? Professional critics and Amazon customers as reviewers of The Inheritance of Loss. Language and Literature, 25(3), $254-278$. https://doi.org/10.1177/0963947016652789

Arthurs, J. and Shaw, S. (2016). Celebrity capital in the political field: Russell Brand's migration from stand-up comedy to Newsnight. Media, Culture \& Society, 38(8), 1136-1152. https:/ / doi.org/10.1177/0163443716635869

Bourdieu, P. (1984). Distinction: A Social Critique of the Judgement of Taste. London: Routledge and Kegan Paul.

Bourdieu, P. (1993). The field of cultural production: Essays on art and literature. Cambridge: Polity.

Braun, V. and Clarke, V. (2006). Using thematic analysis in psychology. Qualitative Research in Psychology, 3, 77-101. https://doi.org/10.1191/1478088706qp063oa

Corse, S. M. and Griffin, M. D. (1997). Cultural valorisation and African American literary history: Reconstructing the canon. Sociological Forum, 12(2), 173-203. https://doi.org/10.1023/A:1024645715453

Crompton, S. (2014). Kate Atkinson: The queen of second chances. The Telegraph. Available at: https://www.telegraph.co.uk/culture/books/10237276/Kate-Atkinson-the-queen-of-second-chances.html 
de Nooy, W. (1999). A literary playground: Literary criticism and balance theory. Poetics, 26, 385-404. https://doi.org/10.1016/S0304-422X(99)00009-1

Driessens, O. (2013). Celebrity capital: Redefining celebrity using field theory. Theory \& Society, 42, 543-560. https://doi.org/10.1007/s11186-013-9202-3

Driscoll, B. (2014). The new literary middlebrow: Tastemakers and reading in the twenty-first century. Basingstoke: Palgrave Macmillan. https://doi.org/10.1057/9781137402929

Ellis-Petersen, H. (2014, 23 May). John Banville: 'Quirke comes from the damaged recesses of my Irish soul'. The Guardian. Available at: https://www.theguardian.com/books/2014/may/23/john-banville-quirke-benjaminblack-bbc

Giles, D. C. (2015). Field migration, cultural mobility and celebrity: The case of Paul McCartney. Celebrity Studies, 6(4), 538-552.

Giles, D. C. (2017). How do fan and celebrity identities become established on Twitter? A study of of social media natives' and their followers. Celebrity Studies, 8(3), 445-460.

Jaffe, M. (2015, November 5). Middlebrow? What's so shameful about writing a book and hoping it sells? The Guardian. Available at: https://www.theguardian.com/books/2015/nov/05/middlebrow-whats-so-shamefulabout-writing-a-book-and-hoping-it-sells-well

Janssen, S. (1997). Reviewing as social practice: Institutional constraints on critics' attention for contemporary fiction. Poetics, 24, 275-297. https://doi.org/10.1016/S0304-422X(96)00010-1

Lamont, M. (2000). The dignity of working men: Morality and the boundaries of race, class and immigration. New York: Russell Sage Foundation.

Levey, N. (2016). Post-press literature: Self-published authors in the literary field. Post45. Available at: http:/ / post45.research.yale.edu/2016/02/post-press-literature-self-published-authors-in-the-literary-field-3/

The Man Booker Prize (2018). Available at: https://www.themanbookerprize.com/fiction/history

Marshall, P. D. (1997). Celebrity and power: Fame in contemporary culture. Minneapolis: University of Minnesota Press.

Norman, W. (2011). Killing the crime novel: Martin Amis' Night Train, genre, and literary fiction. Journal of Modern Literature, 35(1), 37-59. https://doi.org/10.2979/jmodelite.35.1.37

Quirk, S. (2015). Why stand-up matters: How comedians manipulate and influence. London: Bloomsbury. https://doi.org/10.5040/9781472578969

Schwartz, G. (1973). Gershwin: His life and music. Indianapolis: Bobbs-Merrill.

Strauss, A. L. and Corbin, J. M. (1998). Basics of qualitative research: Tecbniques and procedures for developing grounded theory. London: Sage.

Van Rees, C. J. (1987). How reviewers reach consensus on the value of literary works. Poetics, 16, 275-294. https://doi.org/10.1016/0304-422X(87)90008-8 